\title{
Eduardo Cruzat Carrasco. Monseñor Emilio Sthele: el humanismo al servicio de Dios. Santiago de Chile: ESCAPARATE, 2016, 219 PP.
}

\section{DOI: http: / / dx.doi.org/10.29078/ rp.v0i48.703}

Monseñor Emilio Lorenzo Sthele Keller fue un católico alemán que, junto con numerosos religiosos, se desplaza a América Latina teniendo una participación activa en la vida religiosa, pero también en la convulsión social y política que acontece en el continente durante el siglo XX. Se trata de un obispo que sufre la Segunda Guerra Mundial con la muerte de dos de sus hermanos, y con su encarcelación en un campo de prisioneros franceses; presidio en el que descubre su vocación religiosa a través del seminario de teólogos que, de manera insólita, se encarga de proponer en ese controvertido contexto.

Esta experiencia parece forjar al "Obispo constructor", como será conocido más tarde en Ecuador, y al religioso que predica con su ejemplo ofreciendo un diálogo sincero y orientado a la concreción del bien buscado; dialéctica que es reconocida en los distintos e intrincados escenarios de violencia de El Salvador o Colombia, entre otros. Así como en su mediación con la corriente de la Teología de la Liberación que surge, y de la que no huye con su apuesta por la unidad de la Iglesia latinoamericana respetando su propia diversidad.

La vida poco conocida de tan insigne personaje es relatada por Eduardo Cruzat Carrasco mediante un ensayo biográfico que intenta rescatar la relevancia de su experiencia de vida, como aderezo para comprender el pasado reciente en el que se desenvolvió, así como su futuro más inmediato ejemplificado en el acuerdo de paz en Colombia en 2016, y que aconseja la prudencia y capacidad de diálogo que identifica al protagonista de la obra. El autor de este ensayo (profesor de la Pontificia Universidad Católica del Ecuador, Sede Santo Domingo) tiene una dilatada experiencia docente en distintas universidades latinoamericanas (Chile, México y Ecuador), ha ocupado distintos cargos en investigación, y es autor de diversas publicaciones historiográficas.

La obra queda estructurada en cinco capítulos: el primero se encarga de realizar un repaso de su historia en Alemania, proveniente de una familia de campesinos; su adolescencia y juventud viene marcada por el nacionalsocialismo y la fractura de la Iglesia germana, así como la experiencia de pérdida de sus dos hermanos (uno en el campo de batalla y el otro por los propios nazis) y su presidio en un campo de prisioneros francés desde el que orientará su vocación sacerdotal. El segundo capítulo contextualiza su llegada a Latinoamérica tras los estudios de Filosofía y Teología; concretamente, Sthele es destinado inicialmente a Bogotá con la misión de cuidar la parroquia de 
los católicos de lengua alemana en Colombia, y desde la que se proyectará su misión a los demás países de la región latinoamericana. Allí entabla amistad con el sacerdote Camilo Torres Restrepo, quien tiene especial interés en el dominio de la lengua alemana, y del que sufre la frustración de su pérdida, así como el fracaso en su labor persuasiva por alejarlo de la lucha armada.

Sin embargo, su labor de constructor de puentes la consagra tanto en su labor de mediador en la III Asamblea General del Episcopado Latinoamericano en Puebla, en 1979 (México), con la presencia de los partidarios de la Teología de la Liberación, como en la reconocida intermediación para la paz en la guerra civil de El Salvador, que ocupa buena parte del tercer capítulo. Por otro lado, el obispo constructor será esencial en el levantamiento de la parroquia alemana de Bogotá visibilizada en la parroquia de San Miguel, o en la creación de la Prelatura de Santo Domingo de los Colorados (Ecuador) como obispo auxiliar de Quito y vicario episcopal, lo que le hace valedor del calificativo de vicealcalde de Santo Domingo. Entre los distintos proyectos que se cuentan a lo largo del cuarto capítulo se pueden mencionar la consecución de terrenos para el Jardín Botánico Julio Marrero Giráldez de la Universidad Católica, su participación en la construcción de distintos puentes como los del río Toachi y Mulaute, el levantamiento de la institución universitaria o su encargo a los misioneros identes con la aquiescencia de los jesuitas, por mencionar algunos.

Además de su trabajo de construcción y de consecución de fondos nacionales e internacionales, su labor formativa irá acompañada del evangelio, ante la "inculturación" existente en esta latitud, y que será otro de los frentes de trabajo de monseñor.

En el último capítulo se explica las circunstancias en las que se produjo la prohibición del acceso a Colombia del protagonista y su intento de secuestro en la Casa Episcopal en Santo Domingo, cuestión que supuso un punto de inflexión para su regreso a Alemania.

Si bien el autor destaca su lado social y político más que la faceta religiosa del obispo, se puede percibir en el relato de su vida que los acontecimientos que protagoniza provienen de su profundo sentido cristiano desde el cual enfoca su realidad para transformarla. Así, cuidar el diálogo se convierte en una aspiración constante a lo largo de su vida; esta es una esperanza permanente en las personas para que sean capaces de cambiar mediante su ejercicio. Diálogo que, por otro lado, ofrece e intenta formar en su entorno a través de la compasión y la prudencia, como cuando, por ejemplo, el autor relata las visitas de los comandantes de la guerrilla a los heridos en el conflicto de El Salvador.

Esta confianza en la capacidad transformativa del diálogo se constata con su intermediación en la búsqueda de la paz en El Salvador (será pro- 
puesto para el Premio Nobel de la Paz por su trabajo en el acuerdo); en el encuentro que mantiene con Fidel Castro para evitar la internacionalización del conflicto, llegando a ser incluido en una lista de los que debían ser asesinados; o en su participación activa en el canje de prisioneros políticos, al arriesgar su vida en cada encuentro en países como Colombia, Nicaragua, Perú, Chile o Ecuador, por mencionar algunos de los ejemplos que se detallan a lo largo de la obra.

Con el calificativo de "constructor de puentes" es conocido en distintos horizontes de la Iglesia latinoamericana, pues su labor hacia el diálogo desde la prudencia y su participación activa en las transformaciones sociales y políticas cuentan la vida de este obispo; en este caso, desde la mirada de un profesor chileno afincado en Ecuador, que intenta acercase a la experiencia del sacerdote alemán para rescatar su misión y compartirla en tanto orienta su mensaje al cuidado de la dignidad de la persona, consagrada en su esperanza hacia la compasión del prójimo.

Queda a la reflexión del lector el aporte de este "Obispo Constructor" a la cultura política, social y religiosa del Ecuador y de Latinoamérica.

Fernando Lara Lara

Pontificia Universidad Católica del Ecuador, Sede Santo Domingo

\section{Édison Macías Núñez. General Guillermo Rodríguez Lara. Quito: Editogran / Medios Públicos EP, 2017, 300 pp.}

\section{DOI: http:/ / dx.doi.org/10.29078/rp.v0i48.704}

En la operación historiográfica se utilizan los testimonios orales como una herramienta para la reconstrucción del pasado. La hegemonía del presente sobre el pasado en el discurso histórico es del orden de la experiencia y está sostenido, en el caso del testimonio, por la memoria y la subjetividad. ${ }^{1}$

Es importante conocer los diversos datos que se han producido en la memoria de las personas, percibir algo que no sabemos o no tenemos modo de conocer. ${ }^{2}$ El libro intitulado General Guillermo Rodríguez Lara, escrito por el teniente coronel en servicio pasivo Édison Macías Núñez, presenta una reconstrucción histórica estableciendo una conexión entre testimonio y memo-

1. Paul Ricoeur, La memoria, la historia, el olvido (Buenos Aires: Fondo de Cultura Económica, 2013), 65.

2. Alessandro Portelli, "Lo que hace diferente a la historia oral". En La historia oral, comp. por Dora Schwarzstein (Buenos Aires: Centro Editor de América Latina), 37. 